\title{
Holoprosencephaly: an update on cytogenetic abnormalities
}

\section{CLAUDE BENDAVID, VALÉRIE DUPÉ, LUCIE ROCHARD, ISABELLE GICQUEL, CHRISTĖLE DUBOURG AND VÉRONIQUE DAVID.}

Dr. Bendavid, MD PhD, has been working in the Rennes Group since 2002 for Bachelor of Sciences and PhD. He focused most of his thesis work on gene dosage in HPE from cytogenetic FISH classic approach to high throughput CGH study with the aim to find or better delineate HPE loci and detect new candidate genes.

Dr. Dupé is a scientist at the Institut National de la Santé et de la Recherche Médicale (Inserm), she is a member of the IGDR UMR 6061 CNRS, Rennes, France. Her research interests are developmental disorder and brain development.

L. Rochard is a Ph.D student from the University of Rennes, France. She is conducting her thesis work in Pr. David's laboratory working on array CGH analysis and on the functional characterization of holoprosencephaly gene candidates.

I. Gicquel is an engineer of the University of Rennes, France. She is working in the Branch of "genetics of developmental pathologies", UMR 6061 CNRS IGDR. She has developped MLPA and array CGH techniques in this group.

Dr. Dubourg is a faculty member in the branch "Génétique des Pathologies Liées au Développement", UMR 6061 CNRS, IGDR, University of Rennes 1, Faculty of Medicine, Rennes, France, and a hospital member in the laboratory of Molecular Genetics, CHU Pontchaillou, Rennes, France. Her diagnostic and research interests include holoprosencephaly and mental retardation. 
Pr David is the chief of Holoprosencephaly group in the Branch of "genetics of developmental pathologies", UMR 6061 CNRS IGDR, Faculty of Medicine, University of Rennes 1, France. She is the chief of the Molecular Diagnosis laboratory, $\mathrm{CHU}$ Pontchaillou, Rennes, France.

Her research interest mainly concerns HPE, and her clinical research also focuses on iron overload genetic diseases.

*Correspondence to: Véronique David, UMR 6061 CNRS IGDR, Université Rennes1, Faculté de Médecine, 2 av Du Pr. Léon Bernard, CS 34317, 35043 Rennes Cedex, France. Tel: +33 (0)2 232345 43, Fax: +33 (0)2 2323 46 07, Email:veronique.david@univ-rennes1.fr

RUNNING TITLE : holoprosencephaly and cytogenetics 


\section{ABSTRACT}

Holoprosencephaly (HPE), the most common developmental defect of the forebrain and midface, is caused by a failure of midline cleavage early in gestation. Isolated HPE, which is highly genetically heterogeneous, can be due to major chromosomal abnormalities. Initially, karyotype approach led to the identification of several recurrent chromosomal anomalies predicting different HPE loci. Subsequently, several genes were isolated from these critical HPE regions, but point mutations and deletions in these genes were found only in $25 \%$ of the genetic cases. In order to identify other HPE genes, a more accurate investigation of the genome in HPE patients was necessary. To date, high-resolution cytogenetic techniques such as subtelomeric multiplex ligation-dependent probe amplification (MLPA) and microarray-based comparative genomic hybridization (array CGH) have enhanced chromosomal aberration analysis.

In this article, we have updated the cytogenetic anomalies associated with HPE in a map listing all the subtelomeric and interstitial deletions that have been characterized either by karyotype, MLPA or array $\mathrm{CGH}$. The accumulation of recurrent genomic imbalances will lead to the further delineation of minimal critical HPE loci, which is the first step to the identification of new HPE genes.

KEY WORDS: holoprosencephaly, HPE, array CGH, MLPA, candidate loci molecular diagnosis. 


\section{INTRODUCTION}

The etiology of holoprosencephaly (HPE) is heterogeneous and complex, as this developmental disorder can be due to environmental factors, chromosomal aberrations, or genetic anomalies. In this chapter, we focus on the chromosomal aberrations that have been seen in HPE patients.

Chromosome analysis constitutes an excellent approach to identifying the cause of genetic syndromes, particularly for central nervous system (CNS) malformations [Shaffer and others 2007]. The first cytogenetic anomalies reported in HPE were trisomy 13, trisomy 18, and triploidies [Norman 1995; Roessler and Muenke 1998]. Subsequently, advances in cytogenetic techniques such as chromosome banding allowed for higher resolution and for the description of chromosomal anomalies in a collection of patients with HPE. Estimates of the prevalence of karyotype anomalies in live births range from $24 \%$ to $45 \%$ [Bullen and others 2001; Croen and others 1996; Olsen and others 1997]. Numerous isolated HPE case reports show that most of the chromosomes have been implicated, emphasizing the genetic heterogeneity of HPE [Norman 1995; Roessler and Muenke 1998].

Despite this heterogeneity, extensive studies on patients with brain malformations and autosomal deletions demonstrate that four main regions are associated with HPE [Brewer and others 1998; Tyshchenko and others 2008]. Molecular studies of these four recurrent chromosomal regions have resulted in the definition of a minimal critical region and ultimately in the identification of HPEspecific genes. The implication of these regions in HPE was confirmed by the discovery of specific point mutations or deletions in the following genes: Sonic 
Hedgehog, SHH (7q36) (HPE3) [Belloni and others 1996; Dubourg and others 2004; Roessler and others 1996], ZIC2 (13q32) (HPE5) [Brown and others 2001; Brown and others 1998], SIX3 (2p21) (HPE2) [Gripp and others 2000; Pasquier and others 2000; Wallis and others 1999], and TGIF (18p11.3) (HPE4) [Aguilella and others 2003; Gripp and others 2000].

These genes have since constituted the four major genes implicated in the susceptibility to HPE, but have only been found to explain $25 \%$ of the genetic cases, including deletions and microdeletions [Dubourg and others 2007]. This suggests the involvement of other genes, a hypothesis later confirmed by the identification of numerous additional genes: GLI2 (HPE9) [Rahimov and others 2006] [Roessler and others 2003], PATCHED-1 (HPE7) [Ming and others 2002; Roessler and others 2003], DISP1 [Roessler and others 2009a; Roessler and others 2009b], FOXH1 [Roessler and others 2008], NODAL [Roessler and others 2009c], and TDGF1 [de la Cruz and others 2002] (Figure 1). However, mutations or deletions in these genes occur infrequently and are generally associated with HPE microforms. In fact, dysfunction of only one of these genes appears to be not sufficient to cause severe features of typical HPE. Consequently, these genes are thought to have a minor overall effect (present review). Considering this multigenic aspect of the disease, investigation of HPE loci and identification of new HPE genes need to continue.

Originally, the altered chromosomal regions described previously overlapped with one or several $G$ bands and were generally too large to allow for the identification of single candidate genes. Use of molecular screening techniques such as subtelomeric multiplex ligation-dependent probe amplification (MLPA) or microarray-based comparative genomic hybridization (array CGH) has enhanced chromosomal aberration analysis. In the last five years, these techniques have been 
used to delineate critical genomic regions, and their high resolution capabilities have accelerated the identification of novel chromosomal abnormalities. In this article, we summarize the new deleted loci identified by these newer cytogenetic methods and refine the HPE locus map.

\section{THE STATE OF THE KARYOTYPE APPROACH}

Previous analysis of recurrent chromosomal deletions detected by karyotype led to the identification of 12 HPE candidate loci [Norman 1995; Roessler and Muenke 1998]. Subsequently, several genes were isolated from these critical HPE regions, leading to a new nomenclature. The HPE loci previously identified as HPE2, 3, 4, 5, 7 and 9 (OMIM) are now named by their corresponding genes: SIX3, SHH, TGIF, ZIC2, PTCH1 and GLI2, respectively. In addition, there are three recurrent HPE regions that are also considered most likely to be candidate HPE loci, although no specific genes have been identified. These regions have been listed by OMIM as HPE1 (21q22), HPE6 (2q37) and HPE8 (14q13).

In this paper, we have designed a new chromosomal map for HPE to account for these recent changes (Figure 1). This map schematizes the validated HPE gene positions and the cytogenetically abnormal regions for which no specific candidate genes have been identified to date.

This map also represents isolated karyotype abnormalities in 1pter, 3q, and 5pter that may also contain potential candidate genes for HPE [Campeau and others 2008; Schroeder and others 1986; Simovich and others 2008]. It is necessary to exhaustively record all the chromosomal rearrangements that could be validated by further studies; nonetheless, only deletions are reported here in the interest of clarity. 


\section{IDENTIFICATION OF SUBTELOMERIC GENOMIC IMBALANCES BY MULTIPLEX LIGATION-DEPENDENT PROBE AMPLIFICATION (MLPA)}

Bendavid et al. demonstrated that testing for microdeletions is a useful approach in the evaluation of HPE patients as this method increased the diagnosis efficiency from $18 \%$ to $25 \%$ of this cohort. However, since these studies were based on FISH, real time quantitative PCR (qPCR) and quantitative multiplex PCR of short fluorescent fragments, these pilot evaluations were restricted the to known HPE genes [Bendavid and others 2006a; Bendavid and others 2006b].

Of note, two of the microdeleted genes were subtelomeric (TGIF and $S H H$ ), constituting some of the previously described HPE loci [Roessler and Muenke 1998]. Such subtelomeric rearrangements were successfully identified in several studies on mental retardation using a PCR based method named multiplex ligation-dependent probe amplification (MLPA) [Koolen and others 2006; Northrop and others 2005]. These studies led to the conclusion that submicroscopic rearrangements in the subtelomeric regions played an important role in the etiology of congenital defects [Rauch and others 2006] [Ledbetter and Martin 2007].

Therefore, using the same method, subtelomeric screening of HPE patient samples was performed to identify new rearrangements in HPE patients. First, Bendavid et al. tested 10 HPE patients with known deletions: eight SHH deletions (7q36) and two TGIF deletions (18p) [Bendavid and others 2007]. They observed that the previously described microdeletions were not restricted to the gene itself, but instead encompassed several $\mathrm{Mb}$ from the gene to the telomere. Further $\mathrm{qPCR}$ analyses showed that the size of the $7 q 36$ deletions was about $7 \mathrm{Mb}$ in the four 
patients tested. Moreover, five of the $7 q 36$ deletions were associated with gains on another telomere: two on $7 p$, two on $8 p$ and one on $1 p$. This also resulted in the identification of a parental balanced translocation that could be used secondarily for prenatal diagnosis.

Subsequently, a panel of 181 HPE patients without any known chromosomal anomaly was tested and subtelomeric aberrations were detected and confirmed in 8/181 HPE cases (4.4\%, see green bars in Figure 1). One patient had a deletion on $21 \mathrm{q}$, or the HPE1 locus, where no gene is yet firmly identified. The lanosterol synthase gene (LSS) was considered to be the best candidate, but its direct involvement in HPE was never demonstrated [Roessler and others 1999]. Also of note, two unrelated patients showed deletions in 1 pter, a region that has been further implicated by karyotype analysis [Campeau and others 2008]. For the five other patients, a gain and/or loss of chromosomal material was detected in novel subtelomeric regions, not previously reported as candidate HPE loci by karyotype analysis (Figure 1): a 1q gain, a $5 q$ deletion associated with a $17 q$ gain, an $18 q$ deletion associated with an Xq gain, a 15 subcentromeric gain, and a 20p gain with a 22q deletion [Bendavid and others 2007].

The subtelomeric MLPA technique has proven to be a good approach to detect new chromosomal aberrations in HPE patients and confirms that submicroscopic rearrangements were implicated in this disorder. Thus, genome-wide screening for submicroscopic anomalies were needed to test for the presence of rearrangements in the whole genome. 


\section{IDENTIFICATION OF SUBMICROSCOPIC REARRANGEMENTS BY MICROARRAY-BASED COMPARATIVE GENOMIC HYBRIDIZATION (ARRAY CGH)}

Novel genomic technologies such as microarray-based comparative genomic hybridization (array CGH) allow for the mapping of genomic copy number alterations at submicroscopic levels. The resolution of these arrays has progressively increased from $1 \mathrm{Mb}$, using BAC arrays, to approximately $8 \mathrm{~kb}$, when using high density oligonucleotide arrays. Notably, studies on large cohorts of patients with mental retardation and associated facial dysmorphisms were performed using array $\mathrm{CGH}$ and have delineated the major HPE loci in accordance with the previous karyotype results [Shaffer and others 2007]. Therefore, this technology has been applied to a cohort of HPE patients and to case reports.

In this way, a group of 111 HPE patients (64 fetuses and 47 live-born children) with normal karyotype was analyzed using high performance Agilent oligonucleotide arrays [Bendavid and others 2009]. Among these patients, all fetuses had characteristic HPE phenotypes (CNS findings consistent with HPE) whereas of the 47 live-born cases, 32 (68\%) had microforms of HPE and $15(32 \%)$ had a severe form. Chromosomal imbalances not described in the CNV databases were detected in 28 patients (17 fetuses, 11 children) (25\%), out of which 19 had de novo anomalies (17\% of the whole cohort). In total, of these 19 patients with de novo gains or losses, 13 presented isolated deletions, only four showed isolated duplications, and two demonstrated associated gains and losses. Considering that the clinical impact of duplications is more difficult to establish and that gene duplications are less 
deleterious than deletions in HPE cases [Bendavid and others 2009], we will only discuss here the potential implications of the genome losses.

Deletions were found in the $21 \mathrm{qter}$ and $14 \mathrm{q}$ loci, which are previously annotated in the literature [Kamnasaran and others 2005; Roessler and others 1999], reinforcing their potential involvement in HPE. Several new candidate loci not suspected to be involved in the disease at that time were also identified: some were interstitial deletions in 1p, 6q, 10p, 16p, 18q, 20p, 21q and Xp; others were subtelomeric deletions in 19pter and 6qter (Figure 1). The size of these imbalances ranged from $50 \mathrm{~kb}$ to $17 \mathrm{Mb}$ without an obvious correlation with the severity of the phenotype [Bendavid and others 2009].

Although most of these deletions were not redundant, two of them - one in 6qter and one in $10 p$ - were observed in more than one HPE case. Notably, the two overlapping deletions in 6qter mapped a new region, but their large size makes the identification of new candidate genes difficult. In fact, the smallest deletion contains at least 35 genes or putative open reading frames. More significantly, the small (0.1 Mb) deletions observed in 10p12.1 were detected in four HPE patients and contained PATCHED3. This gene belongs to the SHH receptor family and thus represents an excellent candidate. Nevertheless, no point mutation has been found in a cohort of 100 HPE patients (data not published, CD). Also notably, five of the non-redundant deletions are small in size. For instance, the 19pter locus is about $0.4 \mathrm{Mb}$ in size and contains only six genes; unfortunately, none of them is known to be implicated in brain development.

Other deletions included a hemizygous deletion of about $10.4 \mathrm{Mb}$ in size that was detected on another $6 q$ band (6q22-6q23) in an isolated case of middle interhemispheric variant (MIHV) HPE [Abe and others 2009]. In this large area 
comprising many genes, the authors have considered EYA4 as a new HPE candidate gene based on its expression during forebrain development and on its protein interaction with SIX3 [Abe and others 2009]. Nevertheless, only the identification of point mutations or microdeletions in HPE patients will definitively validate the participation of EYA4 in HPE.

\section{THE IMPACT OF ARRAY CGH IN HOLOPROSENCEPHALY RESEARCH}

The array CGH study conducted on the HPE cohort clearly demonstrates that microcytogenetic abnormalities are a frequent cause of HPE with $17 \%$ of de novo anomalies. In addition, this high frequency, regardless of the size, location, and redundancy of the rearrangements, demonstrates that array CGH is an important tool to detect submicroscopic molecular defects in HPE patients.

Nevertheless, the interpretation of the non-recurrent rearrangements should be cautious and their clinical relevance should take into account several parameters. First, the presence of potential copy number polymorphisms (CNP), which account for over $20 \%$ of the human genome, should be ruled out by comparison with the Database of Genomic Variants (http://projects.tcag.ca/variation/), which compiles most known CNPs. Second, it is crucial to test for the presence of chromosomal anomalies in the parents, as it can be postulated that only anomalies that are not associated with a mutation and that arise de novo in the proband are relevant. Alternatively, considering that HPE is a multigenic disease with variable expressivity, inherited genetic anomalies can contribute to an HPE genetic background and thus these inherited deletions should also be recorded (Figure 1, light blue). Finally, due to positional effects, genes localized outside but close to a rearrangement should not be 
discarded but instead be considered as candidate genes. Indeed, it was recently shown that not only hemizygous genes but also normal-copy neighboring genes can show decreased levels of expression [Merla and others 2006]. Therefore, genes flanking a genomic rearrangement should be considered as possible contributors to the phenotype. In addition, the interpretation of these observations is not obvious, as most of the chromosomal aberrations are large. One strategy would be to use software dedicated to the prioritization of candidate genes [Aerts and others 2006] [Tranchevent and others 2008], followed by functional analysis using animal models and research of mutations in these genes.

Beyond these technical pitfalls, array CGH has been shown to be a powerful tool that significantly helped in the identification of genes involved in various pathologic conditions. The first instance was the identification of the gene responsible for CHARGE syndrome, following the localization of a deletion at an 8q breakpoint in an apparently balanced translocation [Vissers and others 2004]. A more recent example is a collaborative work leading to the identification of a new gene (MEF2C) involved in a specific form of mental retardation. In this case, array CGH led to the characterization of a minimal common deleted region in $5 q 14$ in five patients, encompassing the gene MEF2C. Afterward, the identification of a $M E F 2 C$ nonsense mutation in another patient supported its pathologic role [Le Meur and others 2009].

In HPE, the same strategy may lead to a better delineation of minimal critical regions in large recurrent chromosomal deletions that presently do not contain obvious candidate genes or where the major gene implicated to date is controversial. As an example, the 18p deletions are overrepresented among HPE chromosomal aberrations [Overhauser and others 1995], whereas a low rate of TGIF mutations (less than 1\%) is observed in HPE patients [Dubourg and others 2004]. This would 
suggest that this subtelomeric region should be investigated in detail in order to search for other HPE genes. In fact, in the context of a multigenic disease, the implication of several genes in the onset of HPE has to be strongly kept in mind.

Ultimately, using array CGH routinely will enrich the present map (Figure 1) and the catalog of redundant deleted regions will lead to the further delineation of HPE candidate loci, which is the first step to the identification of new HPE genes.

\section{SUMMARY}

Here, we have updated the cytogenetic anomalies associated with HPE in a map listing all the subtelomeric and interstitial deletions that have been characterized either by karyotype, MLPA or array CGH. Considering the high rate of such anomalies observed in HPE, this technique must be integrated in the molecular diagnosis algorithm. The observation of cytogenetic anomalies in patients can lead to the detection of parental balanced translocations, and can subsequently enhance prenatal diagnosis in such families.

This type of compilation must be systematically updated in the next years and will constitute a reference database either for the scientific community or for clinicians who will consult it for diagnostic assistance.

\section{ACKNOWLEDGEMENTS:}

We would like to acknowledge the PHRC interrégional, GIS maladies rares, FMO for funding. We would like to thank the Biogenouest Plateform for technical assistance. 


\section{REFERENCES}

Abe $\mathrm{Y}$, Oka $A$, Mizuguchi $M$, Igarashi $T$, Ishikawa $S$, Aburatani $H$, Yokoyama $S$, Asahara $\mathrm{H}$, Nagao K, Yamada M and others. 2009. EYA4, deleted in a case with middle interhemispheric variant of holoprosencephaly, interacts with SIX3 both physically and functionally. Hum Mutat 30(10):E946-55.

Aerts S, Lambrechts D, Maity S, Van Loo P, Coessens B, De Smet F, Tranchevent LC, De Moor B, Marynen P, Hassan B and others. 2006. Gene prioritization through genomic data fusion. Nat Biotechnol 24(5):537-44.

Aguilella C, Dubourg C, Attia-Sobol J, Vigneron J, Blayau M, Pasquier L, Lazaro L, Odent S, David V. 2003. Molecular screening of the TGIF gene in holoprosencephaly: identification of two novel mutations. Hum Genet 112(2):131-4.

Belloni E, Muenke M, Roessler E, Traverso G, Siegel-Bartelt J, Frumkin A, Mitchell HF, Donis-Keller H, Helms C, Hing AV and others. 1996. Identification of Sonic hedgehog as a candidate gene responsible for holoprosencephaly. Nat Genet 14(3):353-6.

Bendavid C, Dubourg C, Gicquel I, Pasquier L, Saugier-Veber P, Durou MR, Jaillard S, Frebourg T, Haddad BR, Henry C and others. 2006a. Molecular evaluation of foetuses with holoprosencephaly shows high incidence of microdeletions in the HPE genes. Hum Genet 119(1-2):1-8.

Bendavid C, Dubourg C, Pasquier L, Gicquel I, Le Gallou S, Mottier S, Durou MR, Henry C, Odent S, David V. 2007. MLPA screening reveals novel subtelomeric rearrangements in holoprosencephaly. Hum Mutat 28(12):1189-97.

Bendavid C, Haddad BR, Griffin A, Huizing M, Dubourg C, Gicquel I, Cavalli LR, Pasquier L, Shanske AL, Long R and others. 2006b. Multicolor FISH and quantitative PCR can detect submicroscopic deletions in holoprosencephaly patients with a normal karyotype. J Med Genet.

Bendavid C, Rochard L, Dubourg C, Seguin J, Gicquel I, Pasquier L, Vigneron J, Laquerriere A, Marcorelles $P$, Jeanne-Pasquier $C$ and others. 2009. Array$\mathrm{CGH}$ analysis indicates a high prevalence of genomic rearrangements in holoprosencephaly: an updated map of candidate loci. Hum Mutat 30(8):117582.

Brewer C, Holloway S, Zawalnyski P, Schinzel A, FitzPatrick D. 1998. A chromosomal deletion map of human malformations. Am J Hum Genet 63(4):1153-9.

Brown LY, Odent S, David V, Blayau M, Dubourg C, Apacik C, Delgado MA, Hall BD, Reynolds JF, Sommer A and others. 2001. Holoprosencephaly due to mutations in ZIC2: alanine tract expansion mutations may be caused by parental somatic recombination. Hum Mol Genet 10(8):791-6.

Brown SA, Warburton D, Brown LY, Yu CY, Roeder ER, Stengel-Rutkowski S, Hennekam RC, Muenke M. 1998. Holoprosencephaly due to mutations in ZIC2, a homologue of Drosophila odd-paired. Nat Genet 20(2):180-3.

Bullen PJ, Rankin JM, Robson SC. 2001. Investigation of the epidemiology and prenatal diagnosis of holoprosencephaly in the North of England. Am J Obstet Gynecol 184(6):1256-62.

Campeau PM, Ah Mew N, Cartier L, Mackay KL, Shaffer LG, Der Kaloustian VM, Thomas MA. 2008. Prenatal diagnosis of monosomy 1p36: a focus on brain abnormalities and a review of the literature. Am $J$ Med Genet A 146A(23):3062-9. 
Croen LA, Shaw GM, Lammer EJ. 1996. Holoprosencephaly: epidemiologic and clinical characteristics of a California population. Am J Med Genet 64(3):46572.

de la Cruz JM, Bamford RN, Burdine RD, Roessler E, Barkovich AJ, Donnai D, Schier AF, Muenke M. 2002. A loss-of-function mutation in the CFC domain of TDGF1 is associated with human forebrain defects. Hum Genet 110(5):422-8.

Dubourg C, Bendavid C, Pasquier L, Henry C, Odent S, David V. 2007. Holoprosencephaly. Orphanet J Rare Dis 2:8.

Dubourg C, Lazaro L, Pasquier L, Bendavid C, Blayau M, Le Duff F, Durou MR, Odent S, David V. 2004. Molecular screening of SHH, ZIC2, SIX3, and TGIF genes in patients with features of holoprosencephaly spectrum: Mutation review and genotype-phenotype correlations. Hum Mutat 24(1):43-51.

Gripp KW, Wotton D, Edwards MC, Roessler E, Ades L, Meinecke P, Richieri-Costa A, Zackai EH, Massague J, Muenke M and others. 2000. Mutations in TGIF cause holoprosencephaly and link NODAL signalling to human neural axis determination. Nat Genet 25(2):205-8.

Kamnasaran D, Chen CP, Devriendt K, Mehta L, Cox DW. 2005. Defining a holoprosencephaly locus on human chromosome $14 q 13$ and characterization of potential candidate genes. Genomics 85(5):608-21.

Koolen DA, Herbergs J, Veltman JA, Pfundt $R$, van Bokhoven $H$, Stroink $H$, Sistermans EA, Brunner HG, Geurts van Kessel A, de Vries BB. 2006. Holoprosencephaly and preaxial polydactyly associated with a $1.24 \mathrm{Mb}$ duplication encompassing FBXW11 at 5q35.1. J Hum Genet.

Lawson-Yuen A, Berend SA, Soul JS, Irons M. 2006. Patient with novel interstitial deletion of chromosome 3q13.1q13.3 and agenesis of the corpus callosum. Clin Dysmorphol 15(4):217-20.

Le Meur N, Holder-Espinasse M, Jaillard S, Goldenberg A, Joriot S, Amati-Bonneau P, Guichet A, Barth M, Charollais A, Journel H and others. 2009. MEF2C haploinsufficiency caused either by microdeletion of the $5 q 14.3$ region or mutation is responsible for severe mental retardation with stereotypic movements, epilepsy and/or cerebral malformations. J Med Genet.

Ledbetter DH, Martin CL. 2007. Cryptic telomere imbalance: a 15-year update. Am J Med Genet C Semin Med Genet 145C(4):327-34.

Lehman NL, Zaleski DH, Sanger WG, Adickes ED. 2001. Holoprosencephaly associated with an apparent isolated 2q37.1-->2q37.3 deletion. Am J Med Genet 100(3):179-81.

Merla G, Howald C, Henrichsen CN, Lyle R, Wyss C, Zabot MT, Antonarakis SE, Reymond A. 2006. Submicroscopic deletion in patients with Williams-Beuren syndrome influences expression levels of the nonhemizygous flanking genes. Am J Hum Genet 79(2):332-41.

Ming JE, Kaupas ME, Roessler E, Brunner HG, Golabi M, Tekin M, Stratton RF, Sujansky E, Bale SJ, Muenke M. 2002. Mutations in PATCHED-1, the receptor for SONIC HEDGEHOG, are associated with holoprosencephaly. Hum Genet 110(4):297-301.

Norman M. 1995. Congenital malformations of the brain. Pathological, embryonical, clinical, radiological and genetics aspectes. Chapter 9 (Holoprosencephaly: Defects of the Mediobasal prosencephalon):187-221.

Northrop EL, Ren H, Bruno DL, McGhie JD, Coffa J, Schouten J, Choo KH, Slater HR. 2005. Detection of cryptic subtelomeric chromosome abnormalities and 
identification of anonymous chromatin using a quantitative multiplex ligationdependent probe amplification (MLPA) assay. Hum Mutat 26(5):477-86.

Olsen CL, Hughes JP, Youngblood LG, Sharpe-Stimac M. 1997. Epidemiology of holoprosencephaly and phenotypic characteristics of affected children: New York State, 1984-1989. Am J Med Genet 73(2):217-26.

Overhauser J, Mitchell HF, Zackai EH, Tick DB, Rojas K, Muenke M. 1995. Physical mapping of the holoprosencephaly critical region in 18p11.3. Am J Hum Genet 57(5):1080-5.

Pasquier L, Dubourg C, Blayau M, Lazaro L, Le Marec B, David V, Odent S. 2000. A new mutation in the six-domain of SIX3 gene causes holoprosencephaly. Eur J Hum Genet 8(10):797-800.

Rahimov F, Ribeiro LA, de Miranda E, Richieri-Costa A, Murray JC. 2006. GLI2 mutations in four Brazilian patients: how wide is the phenotypic spectrum? Am J Med Genet A 140(23):2571-6.

Rauch A, Hoyer J, Guth S, Zweier C, Kraus C, Becker C, Zenker M, Huffmeier U, Thiel C, Ruschendorf $F$ and others. 2006. Diagnostic yield of various genetic approaches in patients with unexplained developmental delay or mental retardation. Am J Med Genet A 140(19):2063-74.

Roessler E, Belloni E, Gaudenz K, Jay P, Berta P, Scherer SW, Tsui LC, Muenke M. 1996. Mutations in the human Sonic Hedgehog gene cause holoprosencephaly. Nat Genet 14(3):357-60.

Roessler E, Du YZ, Mullor JL, Casas E, Allen WP, Gillessen-Kaesbach G, Roeder ER, Ming JE, Ruiz i Altaba A, Muenke M. 2003. Loss-of-function mutations in the human GLI2 gene are associated with pituitary anomalies and holoprosencephaly-like features. Proc Natl Acad Sci U S A 100(23):13424-9.

Roessler E, Lacbawan F, Dubourg C, Paulussen A, Herbergs J, Hehr U, Bendavid C, Zhou N, Ouspenskaia M, Bale $S$ and others. 2009a. The full spectrum of holoprosencephaly-associated mutations within the ZIC2 gene in humans predicts loss-of-function as the predominant disease mechanism. Hum Mutat.

Roessler E, Ma Y, Ouspenskaia MV, Lacbawan F, Bendavid C, Dubourg C, Beachy PA, Muenke M. 2009b. Truncating loss-of-function mutations of DISP1 contribute to holoprosencephaly-like microform features in humans. Hum Genet 125(4):393-400.

Roessler E, Mittaz L, Du Y, Scott HS, Chang J, Rossier C, Guipponi M, Matsuda SP, Muenke M, Antonarakis SE. 1999. Structure of the human Lanosterol synthase gene and its analysis as a candidate for holoprosencephaly (HPE1). Hum Genet 105(5):489-95.

Roessler E, Muenke M. 1998. Holoprosencephaly: a paradigm for the complex genetics of brain development. J Inherit Metab Dis 21(5):481-97.

Roessler E, Ouspenskaia MV, Karkera JD, Velez JI, Kantipong A, Lacbawan F, Bowers P, Belmont JW, Towbin JA, Goldmuntz E and others. 2008. Reduced NODAL signaling strength via mutation of several pathway members including FOXH1 is linked to human heart defects and holoprosencephaly. Am J Hum Genet 83(1):18-29.

Roessler E, Pei W, Ouspenskaia MV, Karkera JD, Velez JI, Banerjee-Basu S, Gibney G, Lupo PJ, Mitchell LE, Towbin JA and others. 2009c. Cumulative ligand activity of NODAL mutations and modifiers are linked to human heart defects and holoprosencephaly. Mol Genet Metab 98(1-2):225-34. 
Schroeder HW, Jr., Forbes S, Mack L, Davis S, Norwood TH. 1986. Recombination aneusomy of chromosome 5 associated with multiple severe congenital malformations. Clin Genet 30(4):285-92.

Shaffer LG, Bejjani BA, Torchia B, Kirkpatrick S, Coppinger J, Ballif BC. 2007. The identification of microdeletion syndromes and other chromosome abnormalities: cytogenetic methods of the past, new technologies for the future. Am J Med Genet C Semin Med Genet 145C(4):335-45.

Simovich MJ, Bland SD, Peiffer DA, Gunderson KL, Cheung SW, Yatsenko SA, Shinawi M. 2008. Delineation of the proximal 3q microdeletion syndrome. Am J Med Genet A 146A(13):1729-35.

Tranchevent LC, Barriot R, Yu S, Van Vooren S, Van Loo P, Coessens B, De Moor B, Aerts S, Moreau Y. 2008. ENDEAVOUR update: a web resource for gene prioritization in multiple species. Nucleic Acids Res 36(Web Server issue):W377-84.

Tyshchenko N, Lurie I, Schinzel A. 2008. Chromosomal map of human brain malformations. Hum Genet 124(1):73-80.

Vissers LE, van Ravenswaaij CM, Admiraal R, Hurst JA, de Vries BB, Janssen IM, van der Vliet WA, Huys EH, de Jong PJ, Hamel BC and others. 2004. Mutations in a new member of the chromodomain gene family cause CHARGE syndrome. Nat Genet 36(9):955-7.

Wallis DE, Roessler E, Hehr U, Nanni L, Wiltshire T, Richieri-Costa A, GillessenKaesbach G, Zackai EH, Rommens J, Muenke M. 1999. Mutations in the homeodomain of the human SIX3 gene cause holoprosencephaly. Nat Genet 22(2):196-8. 
Figure 1: Diagrammatic representation of the localization of HPE deletions and HPE genes on $\mathrm{G}$ banded chromosomes.

Kaki bars on the left side represent deletions detected by routine karyotype. Green bars on the right side represent rearrangements identified by subtelomeric multiplex ligation-dependent probe amplification (MLPA), with dotted lines where the deletion is not bordered. [Bendavid and others 2007]. Blue bars on the right side represent submicroscopic deletions identified by microarray-based comparative genomic hybridization (array CGH): dark blue denotes de novo deletions, while light blue shows inherited deletions [Abe and others 2009; Bendavid and others 2009]. To demonstrate an exhaustive repertory of the genetics of HPE we have positioned the major (red) and minor (orange) HPE genes: CHR 1 [Campeau and others 2008; Roessler and others 2009b], CHR 2 [Lehman and others 2001; Pasquier and others 2000; Rahimov and others 2006], CHR 3 [de la Cruz and others 2002; Lawson-Yuen and others 2006; Simovich and others 2008], CHR 5 [Schroeder and others 1986], CHR 7 [Belloni and others 1996], CHR 8 [Roessler and others 2008], CHR 9 [Roessler and others 2003], CHR 10 [Roessler and others 2009c], CHR 13 [Brown and others 1998], CHR 14 - HPE8 [Kamnasaran and others 2005], CHR 18 [Gripp and others 2000], and CHR 21 - HPE1 [Roessler and others 1999]. 